\title{
Study of current prescribing pattern of antimicrobial drugs in indoor cases of enteric fever in a tertiary care hospital
}

\author{
Pravin S. Rathod*, Praveenkumar T. Patil, Balwant K. Choure, A. W. Patil
}

\author{
Department of Pharmacology, \\ SBH GMC, Dhule, Maharashtra, \\ India \\ Received: 30 November 2015 \\ Revised: 4 January 2016 \\ Accepted: 7 January 2016 \\ *Correspondence to: \\ Dr. Pravin S. Rathod, \\ Email: drpslohar@rediffmail.com \\ Copyright: (C) the author(s), \\ publisher and licensee Medip \\ Academy. This is an open-access \\ article distributed under the terms \\ of the Creative Commons \\ Attribution Non-Commercial \\ License, which permits \\ unrestricted non-commercial use, \\ distribution, and reproduction in \\ any medium, provided the original \\ work is properly cited.
}

\begin{abstract}
Background: Rational antibiotic prescription is very important to prevent antimicrobial resistance. Hence the present study was conducted to evaluate the prescribing pattern of antimicrobial drugs in indoor enteric fever patients of medicine and paediatric department of a tertiary care hospital.

Methods: A retrospective study of 2 months duration was undertaken during July and August of 2015. A total number of 97 enteric fever patients' case sheets were utilized for our study from medicine and paediatric in-patients department of a tertiary care hospital. The data was analysed and results were expressed as percentage.

Results: Out of 97 enteric fever patients, $54.64 \%$ were females. $13.4 \%$ of paediatric population were suffered because of enteric fever. The incidence of enteric fever was $74.23 \%$ in $13-40$ years. Most commonly prescribed antimicrobials were $3^{\text {rd }}$ generation cephalosporins and fluoroquinolones. $43.30 \%$ patients received more than one antibiotic. Antimalarials chloroquine, artemisinin derivatives and metronidazole were other drugs prescribed to enteric fever patients concurrently for associated clinical conditions.

Conclusions: Interventional programme should focus on the use of rational antibiotic prescription aimed at minimizing unnecessary cost, adverse drug reactions and emergence of bacterial resistance.
\end{abstract}

Keywords: Enteric fever, Prescription pattern, Indoor patients, Cephalosporins, Rational use

\section{INTRODUCTION}

Enteric fever is a major public health problem, causing enormous morbidity and mortality in developing countries, resulting from infection with Salmonella species. The disease is unique to humans characterized by malaise, fever, abdominal discomfort, transient rash, splenomegaly and leucopoenia. The most important and prominent major complications are intestinal ulceration, haemorrhage and perforation. ${ }^{1}$ A changing antibiotic sensitivity pattern of Salmonella species and emergence of multi drug resistance has increased to a great concern. ${ }^{2}$ Traditional drugs such as chloramphenicol, ampicillin and co-trimoxazole were the most effectively used first line drugs for the treatment of enteric fever. However, during the late 1980s and early 1990s the occurrence of multidrug-resistant Salmonella strains resistant to traditional drugs led to the use of fluoroquinolones, particularly ciprofloxacin and third generation cephalosporin for the treatment of enteric fever. ${ }^{3}$ The fluoroquinolones used in therapy of enteric fever are ciprofloxacin, levofloxacin and ofloxacin. Third generation cephalosporins such as cefipime, cefpodoximeproxetil, ceftriaxone and cefixime have shown promising results for the treatment of enteric fever. Resistance is also emerging to these cephalosporins and fluoroquinolones. ${ }^{4}$ The recommendation to use fluoroquinolones as first line therapy for enteric fever, irrespective of sensitivity patterns had profound public health implications for developing countries. ${ }^{2}$ Antibioticresistant strains of Salmonella are becoming prevalent throughout the world; this has resulted in modifications of treatment approaches. Therefore, considering all these factors, this study was carried out to evaluate the prescription pattern of antimicrobial drugs in indoor cases of enteric fever in a tertiary care hospital to achieve the rational and cost effective medical care.

\section{METHODS}

A retrospective observational study was conducted over 2 months in indoor patients of medicine and pediatric department of SBH government medical college and hospital, Dhule. 97 patients who were diagnosed as 
enteric fever cases in one year from April 2014- March 2015 were included in the study. Undiagnosed fever cases and incomplete patients' case sheets were excluded from the study. Source of data was collected from patient's case sheets obtained from medical record section. Patient's details such as name, age, sex, complaints, investigations, treatment details were collected. The study was approved by Institutional Ethics Committee. The data was computed using MS Excel and results were expressed as percentages.

\section{RESULTS}

Enteric fever was predominant in females (54.64\%) (Figure 1).

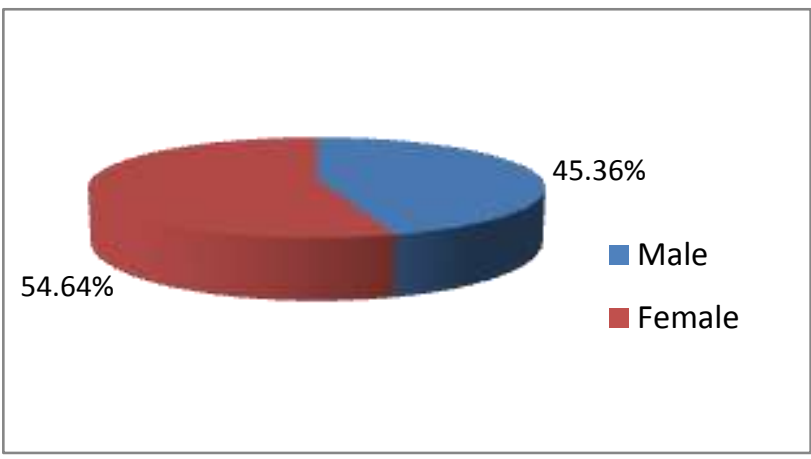

Figure 1: Gender wise distribution of enteric fever patients.

$74.23 \%$ patients were aged between $13-40$ years of age (Figure 2).

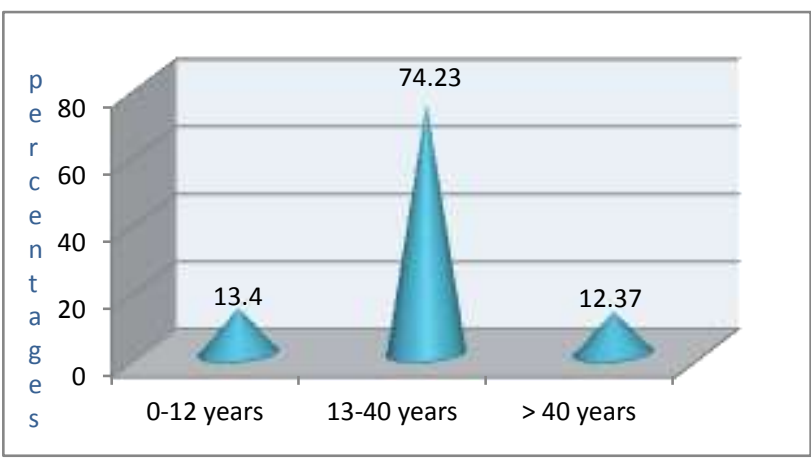

Figure 2: Age wise distribution pattern of enteric fever patients.

Widal test was not done in $76.92 \%$ of paediatric enteric fever patients (Table 1).

Table 1: Widal test pattern in enteric fever patients.

\begin{tabular}{|llll|}
\hline & \multicolumn{2}{l|}{ Widal test done } & $\begin{array}{l}\text { \% of patients } \\
\text { widal test not done }\end{array}$ \\
\hline Male & 28 & No & 26.32 \\
\hline Female & 37 & 09 & 19.15 \\
\hline Pediatrics & 03 & 10 & 76.92 \\
\hline
\end{tabular}

$3^{\text {rd }}$ generation cephalosporins were prescribed to 69 $(71.13 \%)$ patients and fluoroquinolones were prescribed to $34(35.05 \%)$ patients (Table 2$)$.

Table 2: Antibiotic prescription pattern in enteric fever patients.

\begin{tabular}{|llll|}
\hline Antibiotic & Male & Females & Pediatrics \\
\hline Ceftriaxone & 19 & 20 & 7 \\
\hline Ciprofloxacin & 12 & 13 & 9 \\
\hline Cefotaxime & 7 & 12 & 4 \\
\hline Cefuroxime & 2 & 3 & 0 \\
\hline Azithromycin & 0 & 5 & 0 \\
\hline Amikacin & 1 & 1 & 2 \\
\hline Augmentin & 1 & 2 & 2 \\
\hline
\end{tabular}

$16(16.49 \%)$ patients were prescribed oral antibiotics (ciprofloxacin, cefuroxime and azithromycin) at the time of discharge (Table 2).

$42(43.30 \%)$ patients received more than one antibiotic, out of these 31 (31.96\%) patients received combination of 3rd generation cephalosporins and fluoroquinolones (Table 3).

Table 3: Enteric fever patients treated with mono or multi drug therapy.

\begin{tabular}{|lll|}
\hline Drug therapy & n (97) & $\%$ \\
\hline Monotherapy & 55 & 56.70 \\
\hline Multi-drug therapy & 42 & 43.30 \\
\hline
\end{tabular}

$\mathrm{n}=$ number of patients, $\%=$ Percentage

Patients with associated conditions like vivax malaria, liver abscess, and ascites were prescribed chloroquine (6.19\%), artemisinin derivatives (14.43\%) and metronidazole (11.34\%) (Table 4).

Table 4: Drugs prescribed for treating associated diseases in enteric fever patients.

\begin{tabular}{|lll|}
\hline Drugs & n $(97)$ & $\%$ \\
\hline Chloroquine & 6 & 6.19 \\
\hline Artemisinin & 14 & 14.43 \\
\hline Metronidazole & 11 & 11.34 \\
\hline
\end{tabular}

$\mathrm{n}=$ number of patients, $\%=$ Percentage

\section{DISCUSSION}

A prescription provides an insight into a prescriber's attitude of the disease being treated and the nature of the healthcare delivery system in the community. ${ }^{5}$ Rational use of drugs requires that patients receive medications appropriate to their clinical needs, in doses that meet their own individual requirements for an adequate period of time, at the lowest cost to them and their community. ${ }^{6}$

In the present study enteric fever was predominant in females $(54.64 \%)$ and $74.23 \%$ patients were aged 
between 13-40 years (Figure 1, 2) which matches with the previous study results by Rani UM et al. incidence of enteric fever was peak between 15-35 years. ${ }^{7}$ As this age group is socially active, outside eating habits and poor personal hygiene has led to increase in the incidence of enteric fever which is commonly acquired by faeco-oral route.

Even though blood culture is the gold standard for diagnosis of enteric fever, widal test is still widely used for the diagnosis in developing countries as it is simple, gives quick results and cost effective method. ${ }^{8}$ In the present study widal tests was not done in $76.92 \%$ of paediatric patients and were treated just on clinical presentations (Table 1). Hence physicians should be encouraged to treat such patients at least based on widal test results to prevent emergence of drug resistance in near future and to decrease the adverse drug reactions.

In the present study, $3^{\text {rd }}$ generation cephalosporins (ceftriaxone, cefotaxime) were the most commonly prescribed antibiotics for enteric fever (Table 2). Similar results were found in the Rahat SA et al. ${ }^{9}$ however high cost and need for parenteral administration are the disadvantages of cephalosporin therapy. But major concern is emergence of resistance to these cephalosporins. As a result fluoroquinolones are now being used as first line drugs for enteric fever. With increasing resistance to fluoroquinolones also, the policy of empirical treatment of enteric fever needs to be rationalized. ${ }^{10}$ So it might be recommended that proper antibiotic sensitivity testing should be done in diagnosed enteric fever patients to prevent emergence of drug resistance.

In the present study, it was found that $69.23 \%$ paediatric patients were prescribed ciprofloxacin injections which are contraindicated in this age group as they are known to cause arthropathy. ${ }^{10}$ Hence we recommend that physicians should be trained for rational prescription in paediatric patients.

In the present study, $43.30 \%$ enteric fever patients were prescribed multidrug therapy (Table 3) and $31.96 \%$ patients were prescribed combination of $3^{\text {rd }}$ generation cephalosporins and fluoroquinolones which matches with the recommendations made by Brusch JL that ceftriaxone and ciprofloxacin combinations should be used when the bacterial sensitivity pattern is unknown. ${ }^{11}$ Multidrug therapy prescription in our institution could be because it is a tertiary care hospital where most of the critical patients are referred from other centres.

Enteric fever patients in the present study were prescribed chloroquine $(6.19 \%)$, artemisinin derivatives $(14.43 \%)$ and metronidazole $(11.34 \%)$ to treat associated conditions like vivax malaria and associated complications such as liver abscess, and ascites (Table 4). But we recommend, considering the possibility of drug interactions while treating comorbidities, which might increase adverse drug reactions as drug like ciprofloxacin, is a potent drug metabolizing enzyme inhibitor. $^{10}$

\section{CONCLUSION}

The present study provides baseline data of prescribing pattern of antimicrobial agents in indoor enteric fever patients. The study results highlight the problem with the present policy of empirical treatment, without antibiotic sensitivity testing. So the interventional programme should focus on the use of rational antibiotic prescription with the aim of minimizing unnecessary cost, adverse drug reactions and emergence of bacterial resistance. Limitation of the present study was small sample size from a single hospital; so if the sample size is more and taken from different hospitals then study results will be more effective.

Funding: No funding sources

Conflict of interest: None declared

Ethical approval: The study was approved by the Institutional Ethics Committee

\section{REFERENCES}

1. Rani UM. Comparative study of efficacy of cefuroxime and ceftriaxone in enteric fever. IOSR J Dent Med Sci. 2015;14:27-32.

2. Paudel P, Dhungana D, Ghimire S, Khatri B. Susceptibility pattern of salmonella typhi causing enteric fever towards different antimicrobials. World J Pharm Res. 2015;4:1140-67.

3. Adhikari D, Acharya D, Shrestha P, Amatya R. Ciprofloxacin susceptibility of Salmonella enteric serovar typhi and paratyphi A from blood samples of suspected enteric fever patients. Int $\mathbf{J}$ Infection Microbiol. 2012;1:9-13.

4. Capoor MR, Nair D. Quinolone and cephalosporin resistance in enteric fever. J Glob Infect dis. 2010;2:258.

5. Tamuno I, Fadare JO. Drug prescription pattern in a nigerian tertiary hospital. Trop J Pharm Res. 2012;11:146-52.

6. Gopal VD, Krishna RT, Kumar SA, Meda VS, Reddy RK. Prescribing pattern of antibiotics in the general medicine and pediatrics departments of a tertiary care teaching hospital. Int J Pharm Pharm Sci. 2014;6:221-4.

7. Parikh FS. Management of enteric fever in 2012. Med Update. 2012;22:12-4.

8. Rahat SA, Muhammad AR, Hasan MM, Afroz F, Haque HF, Ahmed JU, Ahmed AS. Pattern of antibiotic sensitivity in enteric fever: a tertiary care hospital experience.J Med. 2014;15:122-4.

9. Gupta V, Kaur J, Chander J. An increase in enteric fever cases due to Salmonella Paratyphi A in \& around Chandigarh. Indian J Med Res. 2009;129: 95-8. 
10. Petri WA. Sulfonamides, trimethoprimsulfamethoxazole, quinolones, and agents for urinary tract infections. In Brunton LL, Goodman \& Gilman's the pharmacological basis of Therapeutics, $18^{\text {th }}$ edition. New york: McGraw Hill publishers; 2011;1463-76.
11. Brusch JL. Typhoid fever medication, 2015. http:// emedicine.medscape.com/article/231135medication. Accessed on 27 November 2015.

Cite this article as: Rathod PS, Patil PT, Choure BK, Patil AW. Study of current prescribing pattern of antimicrobial drugs in indoor cases of enteric fever in a tertiary care hospital. Int J Basic Clin Pharmacol 2016;5:159-62. 